\title{
Spasticity after stroke: Physiology, assessment and treatment
}

\author{
Aurore Thibaut ${ }^{1}$, Camille Chatelle ${ }^{1}$, Erik Ziegler $^{2}$, Marie-Aurélie Bruno ${ }^{1}$, Steven Laureys ${ }^{1}$, \& Olivia Gosseries ${ }^{1}$ \\ ${ }^{1}$ Coma Science Group, Cyclotron Research Centre, University and University Hospital of Liège, Liège, Belgium and ${ }^{2}$ Cyclotron Research Centre, \\ University of Liège, Liège, Belgium
}

\begin{abstract}
Background: Spasticity following a stroke occurs in about 30\% of patients. The mechanisms underlying this disorder, however, are not well understood.

Method: This review aims to define spasticity, describe hypotheses explaining its development after a stroke, give an overview of related neuroimaging studies as well as a description of the most common scales used to quantify the degree of spasticity and finally explore which treatments are currently being used to treat this disorder.

Results: The lack of consensus is highlighted on the basis of spasticity and the associated absence of guidelines for treatment, use of drugs and rehabilitation programmes.

Conclusions: Future studies require controlled protocols to determine the efficiency of pharmacological and non-pharmacological treatments for spasticity. Neuroimaging may help predict the occurrence of spasticity and could provide insight into its neurological basis.
\end{abstract}

\author{
Keywords \\ Physiotherapy, stroke, spasticity, treatment, \\ upper motoneuron syndrome
}

\author{
History \\ Received 29 October 2012 \\ Revised 20 April 2013 \\ Accepted 7 May 2013 \\ Published online 25 July 2013
}

\section{Introduction}

Spasticity was first described by Lance [1] in 1980 as 'a motor disorder characterized by a velocity dependent increase in tonic stretch reflexes (muscle tone) with exaggerated tendon jerks, resulting from hyperexcitability of the stretch reflex, as one component of the upper motor neuron syndrome' ( $p$ 485). This description characterizes spasticity during passive movement, but does not take into account its effects on voluntary gestures. In 1994, Young [2] added neurophysiological elements to define spasticity independently of the type of movement: 'a motor disorder characterized by a velocity-dependent increase in tonic stretch reflexes that results from abnormal intra-spinal processing of primary afferent input' (p S12). There is, however, still no consensus for the definition of spasticity and this reflects the complexity and the diversity of the phenomena. This is especially true for post-stroke motor disorders, which can give rise to a considerable variety of symptoms (e.g. clonus, dystonia, muscle weakness, abnormal reflex responses). Spasticity results from impaired reflex function and also induces changes in rheological muscle properties like stiffness, fibrosis and atrophy [3]. The 'upper motor neuron syndrome' can be defined by positive and negative signs [2]. Spasticity is part of the positive signs among other motor symptoms which occur after lesions in the descending corticospinal system such as spastic dystonia (muscle constriction in the absence of any voluntary movement), spastic co-contraction (contraction

Correspondence: Aurore Thibaut, Coma Science Group, Cyclotron Research Centre, University of Liège, Sart-Tilman, 4000 Liège, Belgium. Tel: +32 436623 62. E-mail: athibaut@ulg.ac.be of both the agonist and antagonist muscles resulting from an abnormal pattern of commands in the descending supraspinal pathway), extensor or flexor spasms, clonus, exaggerated deep tendon reflexes and associated reaction $[4,5]$. On the other hand, negative signs are muscle weakness, loss of dexterity and fatigue (Table I).

This disorder is a common symptom after stroke, arising in about $30 \%$ of patients, and usually occurs within the first few days or weeks [6]. However, the onset of spasticity is highly variable and can occur in the short-, medium- or long-term post-stroke period [7]. A study by Wissel et al. [8] showed that $25 \%$ of patients with stroke suffer from spasticity within the first 6 weeks of the event. They also observed that spasticity primarily affects the elbow (79\% of patients), the wrist (66\%) and the ankle (66\%) [8]. In the upper limbs, the most frequent pattern of arm spasticity is internal rotation and adduction of the shoulder coupled with flexion at the elbow, the wrist and the fingers $[9,10]$. In the lower limbs, adduction and extension of the knee with equinovarus foot is the most observed pattern (Figure 1).

A recent study showed that the prevalence of spasticity does not differ between the upper and the lower limbs. Severe spasticity (Modified Ashworth Scale; MAS $\geq 3$ ), though, was observed more frequently in the upper limb muscles [11]. Nevertheless, major spasticity is relatively rare. A high degree of paresis and hypoesthesia at stroke onset has been suggested as one of the predictors for the development of spasticity [11, 12]. Other risk factors were also identified for the development of permanent spasticity after a stroke: (i) any paresis in affected limb, (ii) more severe paresis at 16 weeks compared to the first week, (iii) MAS $\geq 2$ in at least one joint within 6 weeks after stroke, (iv) more than 
Table I. Description of positive and negative signs observed in cases of upper motor neuron syndrome due to stroke [18].

Positive signs

Increased tendon reflexes

Clonus

Positive Babinski sign

Spasticity

Extensor/flexor spasms

Spastic co-contraction (during movement)

Associated reactions and other dyssynergic stereotypical spastic dystonia

Negative signs

Muscle weakness

Loss of dexterity

Fatigability
Result from hyperexcitability of the stretch reflex

Series of involuntary, rhythmic, muscular contractions and relaxations due to a self re-excitation of hyperactive stretch reflexes in the affected muscle

Extension of the big toe, while the other toes fan outwardly in response to rubbing of the sole of the foot. It indicates a lesion of the corticospinal tract

Muscle hypertonia during movement (active or passive), dependent upon velocity of muscle stretch

Spasms occur spontaneously or in response to stimulation (movement of the leg, change of position). The most common pattern of flexor spasm is flexion of the hip, knee and ankle

Agonist and antagonist muscles co-contract simultaneously inappropriately and thus disrupt normal limb movement. This is due to the perturbation of the spinal reflexes that contribute to reciprocal innervation

Remote form of synkinesis due to a failure to inhibit spread of motor activity (e.g. flexion of the elbow simultaneously to flexion of the hip during walking)

Muscles have lower strength due to the loss of corticospinal drive

Loss of hand precise movements, such as opposition of the thumb due to a weakness of the intrinsic and extrinsic hand muscles

Greater effort required to perform a movement leading to tiredness
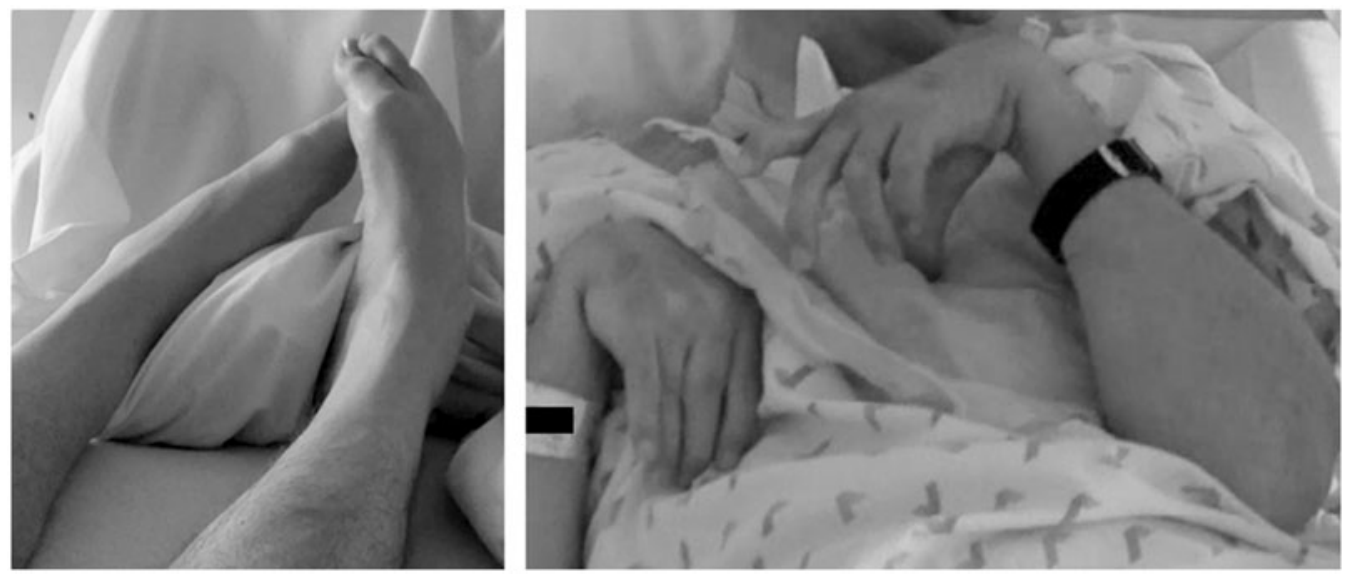

Figure 1. Left: equinovarus feet; right: upper limbs with a spastic pattern in adduction and internal rotation of the shoulder and flexion of the elbow, wrist and fingers.

two joints affected by increased muscle tone, (v) hemispasticity within 6 weeks after stroke and (vi) lower Barthel Index [8].

Spastic symptoms can induce pain, ankylosis, tendon retraction or muscle weakness in patients, which may limit the potential success of rehabilitation [13, 14]. Spasticity can also affect quality-of-life and be highly detrimental to daily function [15]. There is currently a lack of specific guidelines for the stratification and individualization of rehabilitation programmes. First, variables that can reliably predict recovery have to be identified. Second, the pathophysiology of motor disorder following stroke must be explored in order to improve rehabilitation and clarify outcomes.

This review will explore the different hypotheses that attempt to explain the development of spasticity following cortical damage caused by a stroke. This may help to describe the mechanisms underlying the syndrome. A brief overview will then be given of neuroimaging studies of motor disorders following stroke and commonly used scales for quantifying the degree of spasticity. Finally, the most prominent existing treatments and revalidation programmes will be identified and discussed.

\section{Physiopathology}

Spasticity is induced by the dissociation or disintegration of motor responses from sensory input, leading to hyperexcitability of the segmental central nervous system (CNS) [6]. It correlates with the intensity of the sensory input (e.g., degree of stretching) and may be dependent on the CNS lesion's location $[16,17]$. When the balance between inhibitory and excitatory fibres is disturbed, it can result in various aspects of upper limb syndrome, such as hypotonia, dyskinesia or spasticity. Three lesion sites have been suggested to induce spasticity: the brainstem, the cerebral cortex (in primary, secondary and supplementary motor area; SMA) and the spinal cord (pyramidal tract) [18]. Following a stroke only the cortex or, in rare cases, the brainstem, are initially injured and these lesions will often induce spasticity, hyperreflexia and occasionally clonus. The onset of spasticity could be explained by an anarchic neuronal reorganization after brain lesion $[14,17,19]$. The result of this pathological neuronal reorganization may be increased activity in the muscles and exaggerated reflex responses to peripheral stimulation [16]. This hyperactivity could be related to (i) the disinhibition of the normal reflex activities 
(deep tendon reflexes and flexor withdrawal reflexes), (ii) the release of primitive reflexes (e.g., Babinski sign) and (iii) active tonic stretch reflex [16, 20]. Marque et al. [21] showed that a potent excitation of heteronymous group II (fast twitch muscle) quadriceps motor neurons could contribute to spasticity in hemiplegic patients. They observed a facilitation of the $\mathrm{H}$ reflex-a muscle reflex appearing after electrical stimulation of sensory fibres - on the spastic side of the quadriceps, when compared to the unaffected side and to a healthy control population. An improvement of the transmission in the inter-neuronal pathway co-activated by the two groups, I (low oxidative) and II (fast twitch), may result from a change in their descending control pathway in spastic hemiplegic patients. These results support the hypothesis that hyperactivity of the spinal reflex induces spasticity.

For intentional movements, central voluntary motor command may be disturbed at various levels and can be grouped into higher, middle and lower levels of control (Figure 2). The higher level can be sub-divided into two functional entities. The first provides the spatial and temporal representation for guidance of the movement, called 'motor imagination' or 'mental representation', whereas the second is the voluntary drive or motivation to move [22-26]. A stroke in brain areas involved in motility will lead to the activation of lower motor neurons that permit movement, despite a disturbance of the primary execution pathways, by adapting themselves to the pathological situation. One of these adaptations is increased task-related activation in regions not normally recruited for direct movement execution (i.e., SMA cingulate motor areas (CMA), premotor cortex, posterior and inferior parietal cortex, and cerebellum) [27]. These cortical modulations may play a role in the onset and development of spasticity.
As mentioned earlier, the abnormal patterns of motor unit recruitment can be explained by the failure of central voluntary activation $[28,29]$. This is associated with a loss of functional units in the spinal cord as well as a significant reduction of the discharge rate in voluntarily driven motor units within the paretic muscles [30, 31]. Moreover, the alteration of motor neuron recruitment may also be related to direct changes in the properties of spinal motor neurons. Regardless of the respective contributions of supraspinal and spinal mechanisms, loss of normal motor units and firing rate reductions may decrease the efficiency of muscle contraction. This phenomenon could lead to increased effort, fatigue and weakness in voluntary force generation [32]. In addition to the neuronal disturbance, limb immobilization and disuse leads to muscle atrophy, which involves loss of normal weightbearing, sarcomeres, skeletal muscle mass and a reduction in bone mineralization [33, 34] with accumulation of connective tissue and fat [35-38]. These phenomena further exacerbate the disabilities and side-effects induced by spasticity.

\section{Assessment of spasticity}

\section{Behavioural evaluation}

It is important to focus on three issues relating to the functional problem when evaluating spasticity: identifying the clinical pattern of motor dysfunction and its source, identifying the patient's ability to control muscles involved in the clinical pattern and differentiating the role of muscle stiffness and contracture [39].

Several scales have been developed and validated to assess spasticity in patients with brain injury. The two most

\section{MOVEMENT}

LEVELS

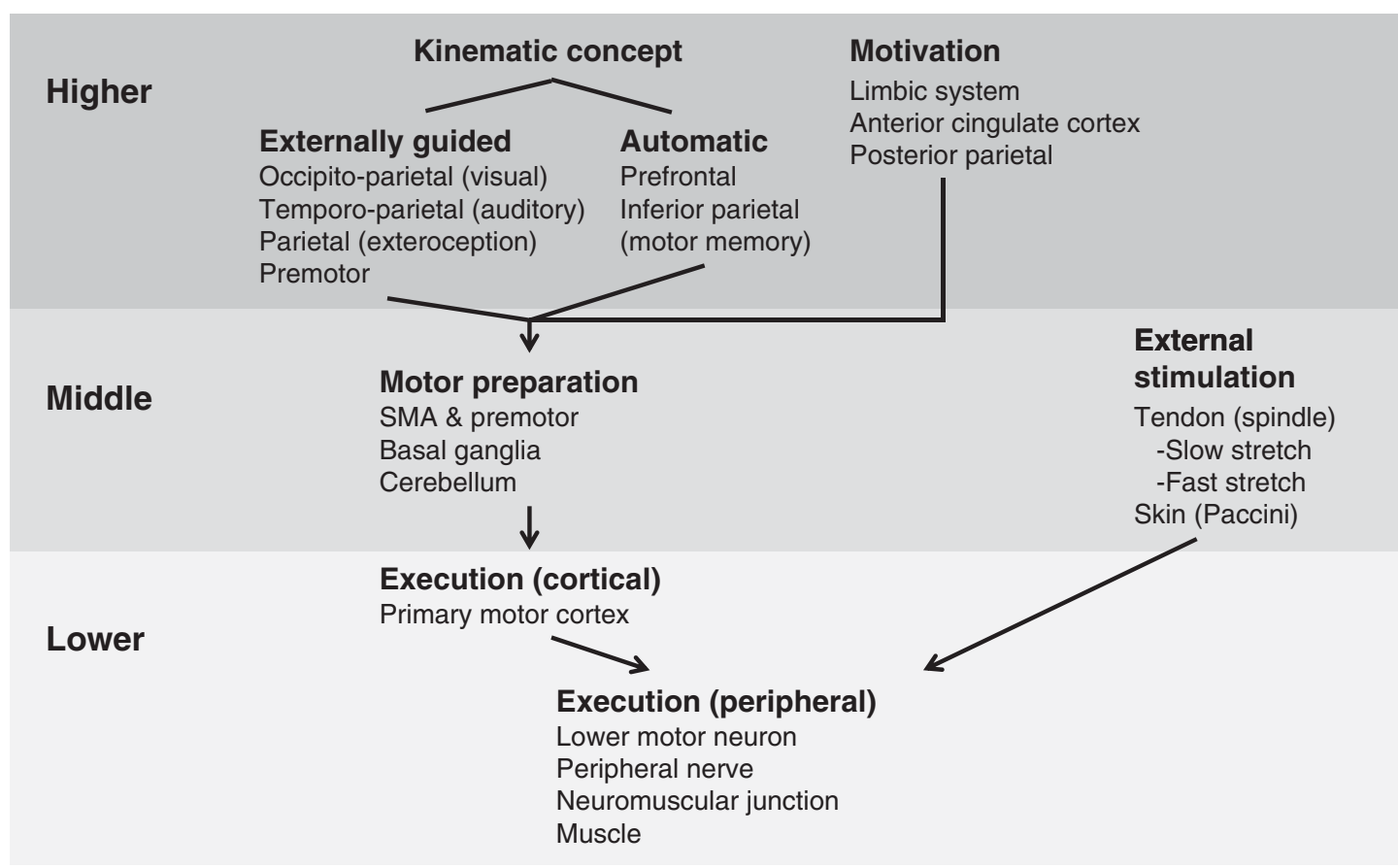

Figure 2. Categorization of voluntary and reflexive movement commands in spasticity. Focused abnormalities in the middle and the lower levels of

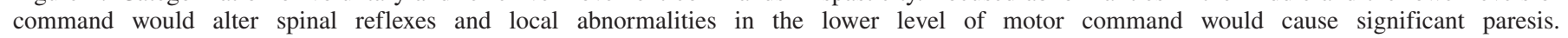
$\mathrm{SMA}=$ supplementary motor area. Adapted from [125]. 
commonly used are the Modified Ashworth Scale [40] and the Modified Tardieu Scale [41, 42]. These scales assess the degree and angle of muscle contraction and, in the case of retraction, the amplitude of the permitted movement.

\section{Modified Ashworth Scale (MAS)}

The Modified Ashworth Scale measures the level of resistance to passive movement, but does not evaluate the velocity of passive joint movement, the angle of contraction outbreak or potential tendon retraction [43] (Table II). The MAS is effective in clinical practice because of its ease and speed of use. Moreover, this scale is widely used in research and has been highly investigated in many studies (e.g., to objectify the effect of a treatment) [5, 44-46]. Unfortunately, validation studies showed only 'moderate' to 'good' intra-rater reliability and 'poor' to 'moderate' inter-rater reliability [45, 47, 48]. Even if this scale seems to measure the resistance adequately, the reduced range of joint motion due to contractures might also limit its reliability [49]. Furthermore, it is not velocitydependent, as Lance's definition of spasticity specified. Nevertheless, it is now established that the MAS evaluates a combination of soft tissue contracture and spastic dystonia, in addition to spasticity itself $[50,51]$.

\section{Modified Tardieu Scale}

In comparison with the Modified Ashworth Scale, the Modified Tardieu Scale does take into account the velocity of passive joint movement, the angle of contraction outbreak and the potential tendon retraction. In this scale, spasticity is assessed with three velocities (low, normal and fast) and the snap angle is reported as the angle of retraction [42, 52, 53] (Table II). Although this scale seems more accurate than the MAS, its validity still needs to be demonstrated [54]. The Modified Tardieu Scale tends to be more sensitive in the detection of post-treatment changes because it measures muscle resistance as well as the velocity of the movement that induces muscular contraction [53, 55, 56]. When comparing the two scales, the distribution of the mean scores correlates poorly [53]. This may be explained by the fact that these two scales measure two different dimensions [53]. The Modified Tardieu Scale is closer to Lance's definition, as it assesses spasticity at three different velocities. Considering its good inter- and intra-subject reliability [45], the Modified Tardieu Scale might be a more appropriate instrument for the measurement of spasticity than the MAS. At present, publications regarding the validity and reliability of the Modified Tardieu Scale are very limited and only concern children with cerebral palsy, rather than adult patients with stroke. In theory, this scale demonstrates several advantages over the MAS, as it uses both a fast and slow speed of movement and incorporates an interval level measure (range of movement), as well as a subjective rating scale. Further studies need to be performed on a larger population to confirm the reliability and the specificity of this scale for assessing spasticity.

\section{King's Hypertonicity Scale}

The King's hypertonicity scale [57] could be a good alternative to measure spasticity and other symptoms of upper motor neuron syndrome because it assesses four areas: presence of increased tone, active range of motion, alternating movements and resistance to passive movement. Each component is evaluated separately and has a score of 1 (normal) to 5 (worst), which gives a total score ranging from 4-20 [57, 58]. Nevertheless, this scale needs to be validated in a wider population.

\section{Tone Assessment Scale}

The Tone Assessment Scale assigns a global spasticity score that integrates passive movement responses, resting posture and reactions associated with the assessment of spasticity in different muscle groups [59]. This scale overcomes some of the shortcomings of the MAS by establishing how tone disorders can affect limb function, such as movements necessary to eat or to walk. It is, however, only reliable for the section relating to response to passive movement at

Table II. The Modified Ashworth Scale [40] and the Modified Tardieu Scale [42].

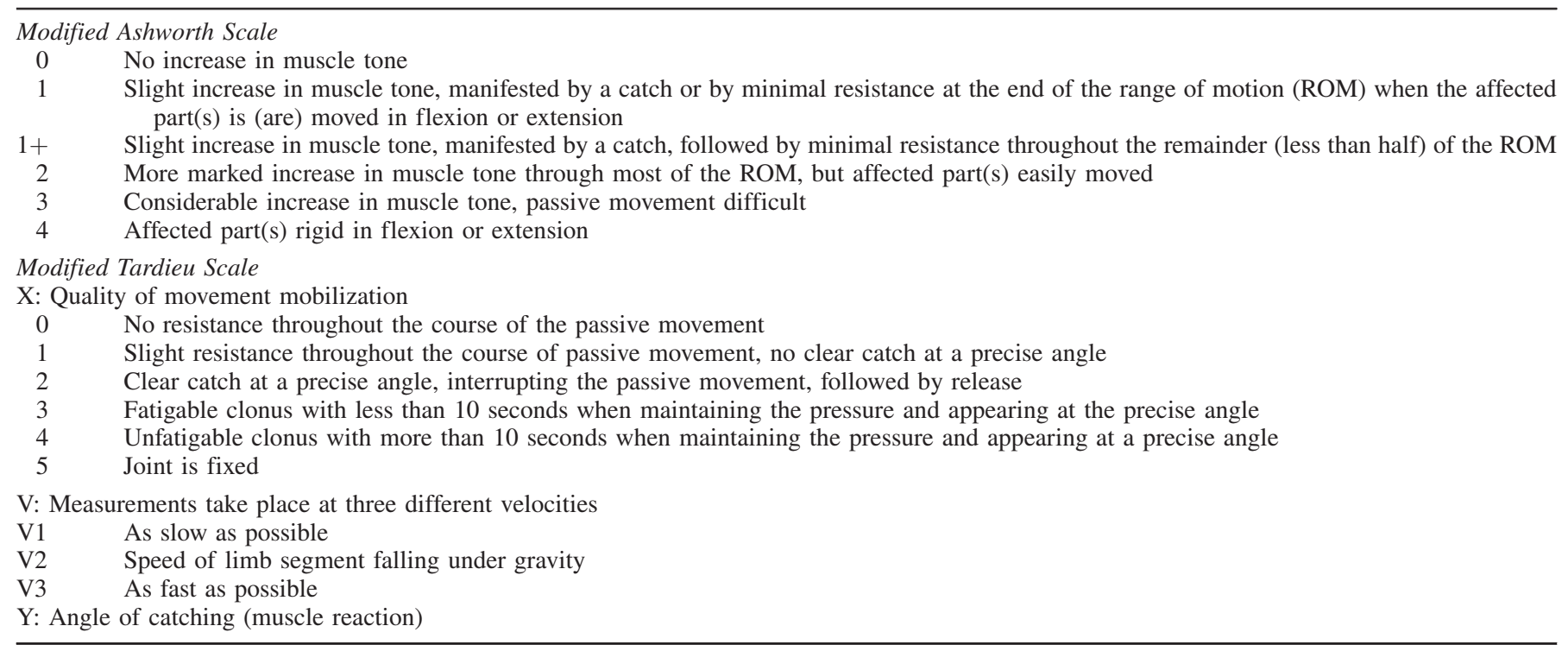


various joints, except the ankle. This scale could be effective for assessing the prevalence of post-stroke spasticity and the relationship between muscle tone and function.

\section{Daily functional assessment scales}

Different scales are used depending on the pattern of clinical practices at the hospital or treatment centre. All these scales do not assess spasticity per se, but give other information about spasticity and its repercussions for pain and daily living. The Barthel Index is a widely used scale to assess activity limitations due to post-stroke motor impairment [60]. It evaluates 10 aspects of activity related to self-care and mobility. This scale also gives an indication about potential patient outcome. About $70 \%$ of patients showing a score lower than 40 will die or suffer from severe disabilities after 6 months, whereas $95 \%$ of patients with a score higher than 80 will recover $[60,61]$. Other scales, such as the Patient's Disability and the Carer Burden Rating Scales, have also been proposed $[45,62]$ to assess the degree of disability caused by spasticity. The Patient's Disability Scale assesses a patient's ability to care for their spastic limb (dressing, hygiene, etc.) and to use it functionally (e.g. for walking) [45]. The Carer Burden Rating Scale also assesses care tasks, such as dressing and maintaining hygiene, but when a caregiver performs them [62]. With a similar approach, Brashear et al. [45] developed the Disability Assessment Scale, which assesses four domains of potential disability: hygiene, dressing, limb position and pain. Studies have shown that it has good inter- and intra-rater reliability, although its validity has not yet been determined [45].

It is important to stress that spasticity is not the only symptom that could be involved in motor impairment; the other signs of upper motoneuron syndrome also affect patients in their activities of daily life. Indeed, as said in the introduction, patients with stroke may suffer from dystonia, rigidity or co-contraction. Moreover, spasticity and the other positives signs of upper motoneuron syndrome could diminish a patient's ability to control their muscles during a specific movement. Finally, if stiffness, ankylosis and contracture arise, they could lead to functional difficulties and even induce joint range of motion limitation or joint fixation, mainly in triple flexion for the upper limbs and extension for the lower limbs. Table III summarizes the most common patterns of upper motor neuron syndrome [39].

\section{Electrophysiological measures}

Para-clinical tools complement behavioural measures by objectively quantifying spasticity in a more sensitive and reliable way. Techniques that register synaptic reflexes with electromyography (EMG) can be classified in two subgroups: (i) EMG responses to electrical stimuli such as the Hoffmann reflex (H-reflex) and F-wave and (ii) EMG responses to mechanical stimuli such as the Tendon reflex (T-reflex) and polysynaptic responses [63]. The H-reflex allows assessing the excitability of the alpha motoneuron. The F-wave is a response of small amplitude that follows the M response (i.e., direct motor response caused by the stimulation of alpha fibres). Recording the H-reflex, F response and H/M or $\mathrm{F} / \mathrm{M}$ ratios can provide quantitative information about spasticity [64]. In patients with spasticity, the hyperexcitability of the stretch reflex is neurophysiologically characterized by an increase of the ' $\mathrm{H} \max / \mathrm{M}$ max' ratio. This could be due to an exaggerated facilitation of the H-reflex to voluntary muscle contraction and/or to the lack of inhibition associated with muscle relaxation [65]. The T-reflex quantifies the stretch reflex by recording muscle responses to tendon percussion. The amplitude of the response depends on the gain of the primary neuromuscular spindle nerve endings [66]. Finally, the study of Ib fibre inhibition can also be useful for detecting spasticity [67]. Altogether, these measurements are helpful for evaluating the degree of spasticity.

\section{Gait and movement analysis}

Gait laboratories facilitate how a victim of a stroke walks, adapts and compensates and can help assess the functional repercussions of spasticity. A gait laboratory has several cameras placed around the patient all linked to a computer. The patient has markers at various specific points on their body (e.g., iliac spines of the pelvis, condyles of the knee) and the computer calculates the trajectory of each marker. The spatial distribution of forces can be measured with pedobarography equipment. EMG can be added to investigate the activation timing of muscles and assess their contribution to gait (e.g., on the quadriceps). These analyses provide a complete breakdown of the gait movements and can help to highlight movement compensation and re-evaluate the patient after a rehabilitation programme.

\section{Neuroimaging}

To the authors' knowledge, only a few neuroimaging studies have been performed to assess spasticity. Some studies have investigated the effects of Botulinum Toxin A (BoNT-A) on spasticity in patients post-stroke. They have shown a decrease in activation of the posterior cingulate cortex and precuneus [68] following treatment and a decrease in activation in contralateral frontoparietal areas including inferior frontal, post-central and middle frontal gyrus, with activation limited to midline and contralateral sensorimotor cortices [69].

Other studies on motor disorders suggested that several brain areas are involved in the recovery of motility after a stroke [70]. An early study, using Positron Emission Tomography (PET), showed a correlation between the movement recovery in hemiparesis patients and increase of brain metabolism in the parieto-premotor areas [70]. These observations further implicate a role of this network in motor disorders following a brain lesion. Another PET study, performed by Struppler et al. [71], also showed that the improvement in a motor task (finger extension) was related to an increase of neural activation in this network, which is known to be functionally interconnected with motor areas involved in the control of arm and hand movements. In this study, an additional increase of the brain metabolism was also observed in the SMA and CMA [71]. Moreover, patients who recovered well (improvement in several motor and disability scales) showed changes within the motor system which occurred early and evolved into a more normal pattern of 
Table III. Summary of the most common patterns observed in the upper motor neuron syndrome, the muscles involved and the most observed side-effects. Adapted from [6].

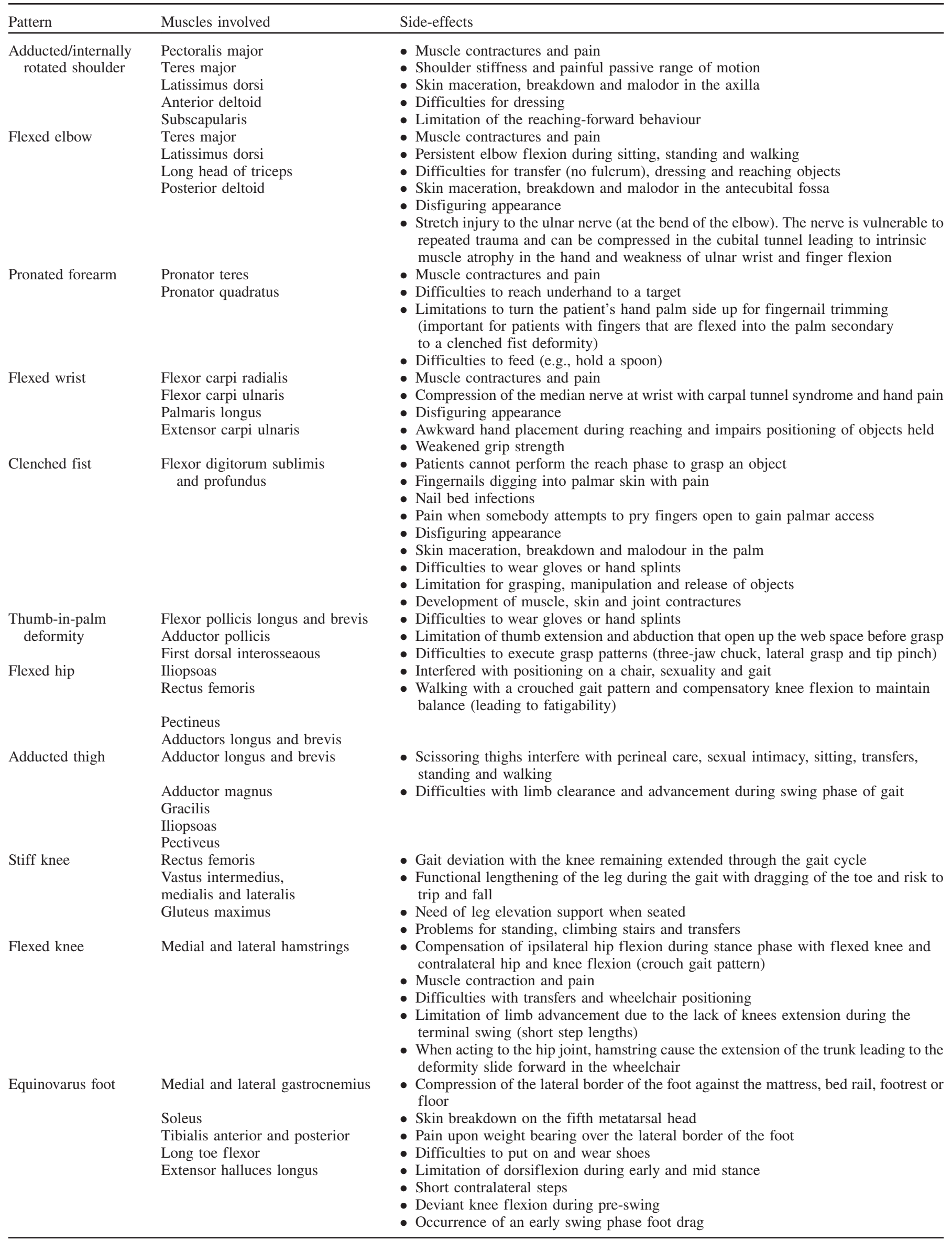


activation, whereas little changes occurred in those with severe impairment or poor recovery.

Plasticity changes appeared primarily in the SMA in patients with good recovery, highlighting the importance of this area in the process of recovery and the dynamic nature of the modification observed. Studies using Magnetic Resonance Imaging (MRI) also note the crucial role of the SMA/CMA in the early phase of good motor recovery, as well as an increase in activity in the premotor cortex, the secondary somatosensory cortex contralateral to the affected hand and in the superior posterior regions of the cerebellar hemisphere bilaterally [72]. Furthermore, motor recovery has been correlated with activity in the primary motor cortex and SMA/CMA that becomes more normal over time [27]. These studies suggest that early changes in motor brain areas with efficient neuronal plasticity lead to better motor recovery, whereas spasticity seems to be a predictive factor of poor motor recovery after stroke [27, 72].

\section{Treatment}

Therapeutic interventions include physical therapy, occupational therapy, self-rehabilitation, orthoses equipment and assistive devices, pharmacological treatment, orthopaedic surgery and neurosurgery. This study describes various nonpharmacological patient rehabilitation therapies as well as the most common pharmacological treatments and surgery intervention.

\section{Non-pharmacological treatment}

\section{Physical therapy}

The basic treatment for all patients presenting spasticity is physical therapy [73, 74]. Limiting muscle contractures and reducing hyperactivity for at least a short period of time can be helpful. The aim of stretching is to improve the viscoelastic properties of the muscle-tendon unit and to increase its extensibility. Other structures can also be put under tension, such as tendons or connective, vascular, dermal or neural tissue $[75,76]$. There is, however, no consensus about the optimal frequency, intensity, velocity and duration of stretching. A recent systematic review of the effectiveness of stretching to treat and prevent contracture in patients with brain injuries concluded that stretching does not induce significant changes in joint mobility, pain, spasticity or activity limitation [77]. Casting, a stretching method that immobilizes the limb in a stretch position, induces prolonged muscle stretching. This technique aims to improve muscle length, increase joint range of motion and to reduce contracture, pain and spasticity [78]. There are no guidelines yet, nor any scientific evidence that this method can reduce spasticity caused by neurological disorders [79]. Beside muscle stretching, muscle strength training is also used to recover functional motricity [80]. One of the most widely used approaches is the Progressive Resistance Strength Training, although, at this time, there is no gold standard for strengthening protocols [81].

Other physical therapies are used to decrease spasticity and improve motor function, such as Bobath technique, which is based on the reduction of spasticity and promotive postural reflexes prior to facilitating voluntary activity in paretic muscles through attention to trunk posture as well as controlled muscle stretch at the limbs [82]. Nonetheless, only a few studies showed that this technique is efficient to reduce spasticity in patients suffering from a stroke [83], and its effectiveness seems to be limited [84]. Additional therapies, like hydrotherapy, cryotherapy, thermotherapy, vibratory stimuli or neurodevelopmental inhibitory techniques and robotics, are used to relax muscles and reduce the intensity of spasticity. Future studies should also be investigated to determine their effectiveness [81].

\section{Orthoses}

Orthoses are frequently used in complement with physiotherapy sessions. Several types of orthoses (also called splints) exist but, as with physiotherapy, no practical guidelines have been defined so far. The aims of splinting are reductions in spasticity and pain, improvement of function, compensation for protective sensation and prevention of contracture and deformity [85]. The principal advantage of orthoses is the duration of their effectiveness, because they can be placed and left for several hours without the presence of a physiotherapist or nurse. Nevertheless, their efficacy is not yet proven by any double-blind studies and they have recently failed to provide any significant improvement in spasticity of the wrist flexor or range of wrist motion, when they were applied to the hand [86].

\section{Transcutaneous Electrical Nerve Stimulation (TENS)}

TENS is another physical treatment that consists of electrical stimulations administered over the spastic region, the spinal dermatome or the peroneal nerve $[74,87]$. This technique has been shown to reduce spasticity in antagonist muscles [8890]. The effect seems to be related to the production of $\beta$-endorphins, which may decrease the excitability of motor neurons. It may also reduce nociceptive inputs, as suggested by the gate control theory, by regulating the transmission of pain impulses [91, 92]. Moreover, it has been suggested that TENS could facilitate cortical synaptic reorganization and motor output by increasing sensory input, due to the stimulation of large diameter $\mathrm{A}_{\beta}$ fibres. The efficiency of TENS still needs to be further investigated through randomized controlled trials. Other stimulation methods, such as ultrasound and transcranial direct current stimulation, which have, until now, only been used in research, have shown promising positive effects against spasticity [93, 94]. Further studies are still needed to determine the most efficient parameters and to understand the sustained mechanisms that underlie these stimulation methods.

\section{Pharmacological agents}

Anti-spastic treatment should be introduced when the patient suffers from motor disability due to spasticity. After a stroke, motor hyperactivity is the only motor disorder (see the pathophysiology section) that can benefit from drug treatment. Medication should be tailored according to the lesion area (e.g., cortical, spinal cord) and the intended effects. Pharmacological treatments either act on the CNS or directly 
Table IV. Dosing, mechanism of action and side-effects of pharmacological treatment of spasticity. Adapted from [98, 108, 126].

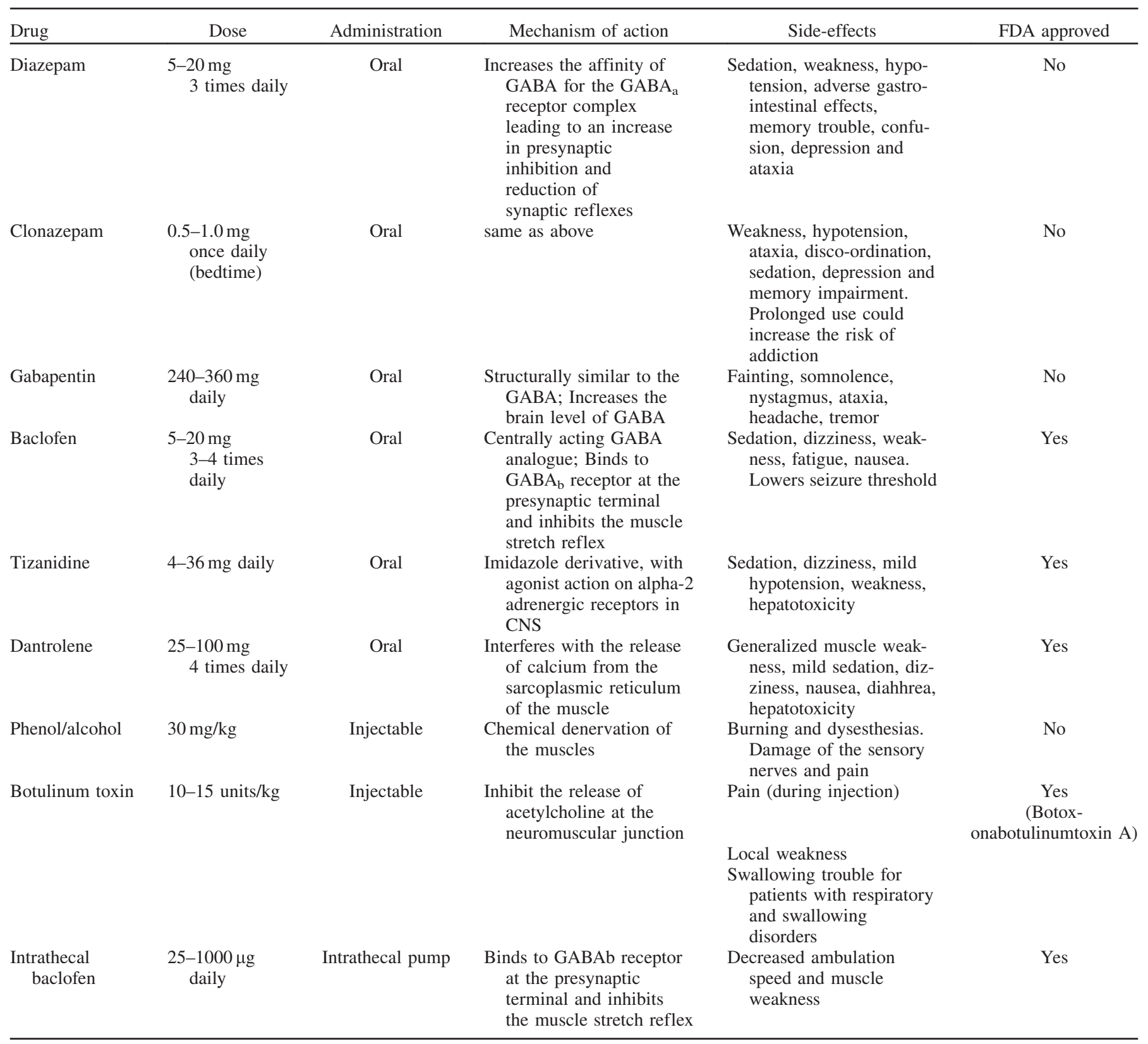

on the muscles. Several treatments aim to reduce muscle tone, either through oral or injectable administrations or through an intrathecal pump. Their efficiency, however, remains controversial and not well understood (Table IV).

\section{Oral treatments}

- Baclofen, a gamma-Aminobutyric acid (GABA) agonist, is the most commonly administered oral treatment against spasticity. Baclofen crosses the blood-brain barrier and binds at the $\mathrm{GABA}_{\mathrm{b}}$ receptors of the spinal cord. Potential adverse effects such as sedation, fatigue and drowsiness lead to oral drugs being considered as a second treatment line in patients with stroke, especially during early rehabilitation [95-97]. Despite its widespread use in patients with severe brain injuries, its efficiency for combating spasticity still need to be widely proven [97].
- Benzodiazepines, such as diazepam or clonazepam, increase the affinity of GABA for the $\mathrm{GABA}_{\mathrm{a}}$ receptor complex. This leads to an increase in pre-synaptic inhibition and, therefore, a reduction of spinal reflex pathway [98]. Although they reduce muscle hypercontraction, these agents also induce muscle weakness and drowsiness [98]. Since past studies on benzodiazepines in post-stroke rehabilitation showed some detrimental effects, they are no longer recommended [99].

- Gabapentin is an anti-convulsant structurally similar to GABA. Although this drug is usually used to treat neuropathic pain, it has been shown to be effective for decreasing spasticity at high doses (e.g. 2400-3600 mg per day) $[81,98,100]$. Gabapentin intake seems to result in increased brain levels of GABA. However, its exact mechanism of action is not well understood. This agent has several adverse effects such as fainting, somnolence, nystagmus, ataxia, headache and tremor [98]. 
- Tizanidine, an adrenoceptor agonist, is another centralacting drug that increases the pre-synaptic inhibition of motor neurons [101, 102]. This pharmacological agent is used less often than other drugs like Baclofen, perhaps because of its novelty or potentially its side-effects (e.g., sedation, hypotension, asthenia, dizziness, hallucination or hepatotoxicity) [103, 104].

- Dandrolene sodium is a muscle relaxant that acts by binding the ryanodine receptor and affects calcium release, specifically in skeletal muscle to inhibit excitation/contraction coupling, thereby reducing spasticity [105]. In doses greater than $200-300 \mathrm{mg}$ per day it also has a sedative effect [106].

It is important to stress that all long-term treatments will have to be revised (e.g., for therapeutic windows and dose changes). Indeed, the patient's condition can change (e.g., increased spasticity or, on the contrary, surgery or botulinum toxin injection which reduce spasticity). Moreover, the patient can also present a habituation to the treatment.

\section{Injectable treatments}

- Phenol and alcohol are neurolytic agents which induce chemodenervation [107]. The recommended concentration is $5-7 \%$ for phenol and $45-100 \%$ for alcohol. Unfortunately, dysesthesia and soft-tissue fibrosis can occur because these substances lack specificity [98].

- Botulinum toxin (BoNT) agents, administered by intramuscular injection, are also available for the treatment of localized spasticity and have been shown to increase patient's ability to actively mobilize their upper and lower limbs and improve their autonomy (e.g. self-care, walking) [108-110]. Electrostimulation is the most strongly recommended localization technique, to precisely identify the muscle that needs to be treated, BoNT-A specifically inhibits acetylcholine release at the neuromuscular junction, thus reducing muscle contractions [111]. In comparison with phenol and alcohol, BoNT-A is more selective due to the easy titration and administration [98]. The effectiveness of BoNT-A for reducing spasticity in upper limbs (elbow, wrist and fingers) as assessed by the MAS and on functional abilities (e.g., Barthel Index), was proven by several randomized double-blind placebo-controlled studies $[110,112,113]$. It also seems to be effective for decreasing spasticity in the lower limbs (foot and calf) [114]. Moreover, Simpson et al. [115] showed that BoNTA is safer and more effective than Tizanidine, reporting a higher reduction of muscle tone in the upper limbs and lower incidence of side-effects. Aside from acting on the tonus and increasing the efficiency of physiotherapy techniques, this injection can also have an analgesic effect [116].

Only Botox (onabotulinumtoxin A) is approved by the United States' Food and Drug Administration (FDA) for the treatment of upper limb spasticity in adults at the elbow (biceps), wrist (flexor carpi ulnaris and radialis) and fingers (flexor digitorum profundus and flexor digitorum sublimis). There are three other botulinum toxins available (abobotulinumtoxinA [Dysport],
incobotulinumtoxinA [Xeomin] and rimabotulinumtoxinB [Myobloc]), but none of them are currently FDA approved for this purpose.

Below one can find recommendations made by Sheean et al. [117] for the use of BoNT-A as a treatment of upper limb spasticity:

- The effects of spasticity should be described at the level of both impairment and impact on function (active and passive).

- Treatment decisions should be based on individual evaluation, including chronicity, severity and distribution of the spasticity and weakness; the presence and severity of co-morbidities, such as contracture; the availability of support; and the goals of treatment.

- Distinguish hypertonia caused by spasticity from that of soft tissue changes.

- BoNT-A treatment is appropriate for the reduction in pain and improvement in passive function in patients with upper limb spasticity, using individualized injection patterns and treatment goals established for each patient.

- Patients most likely to benefit from BoNT-A have focal or multifocal upper limb spasticity.

- BoNT-A treatment should: be viewed as adjunct to a neurorehabilitation programme, be considered in the absence of absolute contraindication, commence when the spasticity is a significant impediment to therapy or when the problem is worsening or plateaus.

- Muscle localization may be based on surface anatomy, EMG, neuromuscular electrical stimulation, ultrasound or other appropriate imaging (e.g., Computed Tomography).

- Consider the possibility of diffusion locally and systemically and the risks of needle injury to other structures.

- Care should be taken when injecting the proximal upper limb in patients with compromised swallowing.

Concerning BoNT-B, no encouraging results have been reported its efficiency for upper limbs [118] and no study on its efficiency for the lower limbs has been done yet. In conclusion, BoNT-A can be useful for reducing spasticity and have less side-effects than other injectable drugs, such as phenol and alcohol [108, 119].

\section{Intrathecal baclofen pomp}

This technique permits direct administration of GABA agonist in the spinal cord in order to inhibit spasticity while minimizing side-effects. Its efficiency has been shown in cases of spinal cord injury and multiple sclerosis, but not yet in a patient with stroke $[120,121]$. It is also more often used for spasticity of the lower limbs and the trunk. Unfortunately, in patients presenting severe spasticity this treatment showed a lack of efficiency in decreasing muscle hyperactivity. Moreover, it can induce various related side-effects, such as vigilance and respiratory disorders in the case of overdosing, cerebrospinal fluid leak with headache, catheter migration, disconnection or blockage and infection [122].

\section{Surgical treatment}

Surgical treatment of spasticity is mainly used for severe spasticity or for the after-effects induced by spasticity that become functional impairments (e.g. irreductible equinus 
varus foot). These surgeries involve myelotomy, tenotomy and cordectomy to decrease muscle contraction [123]. Surgical results, though, are variable and depend on the patient. Osteotomies could also correct articulation deformity. Orthopaedic surgery can be used to decrease the side-effects of spasticity, mainly by tendon adjustment, like lengthening, releasing or transferring a specific tendon. Selective dorsal rhizotomy is mainly performed for the treatment of spasticity in children with cerebral palsy [124], but it can be employed to treat spasticity of the legs that interferes with movement or positioning. The abnormal sensory nerve rootlets are identified and sectioned, while the motor nerves remain intact. These techniques are helpful in optimizing function, especially hand opening (fingers flexor tendon) and walking (triceps surea tendon), and could prevent contractures.

\section{Conclusion}

Spasticity affects more than one out of four patients after a stroke [8]. The complexity and the diversity of spasticity make the identification of its underlying mechanisms and predisposing factors difficult. Comprehension of the spasticity phenomenon is essential so that drugs and therapeutic strategies can be developed to efficiently treat causes rather than symptoms. Failures in motor neuron activation and alterations in spinal motor neurons appear to be two major components of the pathophysiology behind paresis following a brain lesion. However, motor impairment due to paresis is greatly exacerbated by the muscles, the joint contracture and the changes in muscle contractile properties caused by immobilization. In addition, chronic disuse causes an alteration of CNS function that further reduces the ability to voluntarily recruit motor units [125]. Neuroimaging studies highlight the importance of some specific brain areas (e.g., SMA, CMA and secondary somatosensory cortex) in the development of spasticity and other motor disorders. Nevertheless, these motor issues are not well understood and further neuroimaging studies, which allow for non-invasive investigation of brain dysfunction without patient discomfort, should be done to monitor the onset and development of spasticity.

In terms of treatment, physical therapy and pharmacological treatment are essential for avoiding retraction and joint fixation, but, to date, except for BoTN on the upper limb, there are no scientific guidelines for the application of different therapies in patients suffering from spasticity. Therefore, clear guidelines need to be developed regarding the revalidation of post-stroke patients with spasticity through physical therapy, pharmacological treatment and surgical intervention. To do so, double-blind randomized controlled studies on pharmacological and non-pharmacological treatments should be performed to improve insight into spasticity.

\section{Declaration of interest}

The authors report no conflicts of interest. This study was supported by the National Funds for Scientific Research (FNRS), James S. McDonnell Foundation, Mind Science Foundation, European Commission (Mindbridge, DISCOS, DECODER \& COST), Fonds Léon Fredericq, Concerted Research Action (ARC 06/11-340), Public Utility Foundation
'Université Européenne du Travail', 'Fondazione Europea di Ricerca Biomedica', EU Marie Curie Initial Training Network Grant PITN-GA-2009-238593 and the University of Liège. AT, CC and EZ are research follows, MAB and OG are postdoctoral researchers, and SL is research director at FNRS.

\section{References}

1. Lance J. Spasticity: disorders motor control. In: Feldman RG, Young RP, Koella WP editors. Symposium synopsis. Miami, FL: Year Book Medical Publishers; 1980.

2. Young RR. Spasticity: A review. Neurology 1994;44(S9):S12-S20.

3. Dietz V, Sinkjaer T. Spastic movement disorder: Impaired reflex function and altered muscle mechanics. Lancet Neurology 2007;6: $725-733$.

4. McComas AJ. Human neuromuscular adaptations that accompany changes in activity. Medicine \& Science in Sports \& Exercise 1994; 26:1498-1509.

5. Sommerfeld DK, Eek EU, Svensson AK, Holmqvist LW, von Arbin MH. Spasticity after stroke: Its occurrence and association with motor impairments and activity limitations. Stroke 2004;35: 134-139.

6. Mayer NH, Esquenazi A. Muscle overactivity and movement dysfunction in the upper motoneuron syndrome. Physical Medicine \& Rehabilitation Clinics of North America 2003;14:855-883, vii-viii.

7. Ward AB. A literature review of the pathophysiology and onset of post-stroke spasticity. European Journal of Neurology 2012;19: 21-27.

8. Wissel J, Schelosky LD, Scott J, Christe W, Faiss JH, Mueller J. Early development of spasticity following stroke: A prospective, observational trial. Journal of Neurology 2010;257:1067-1072.

9. Hefter H, Jost WH, Reissig A, Zakine B, Bakheit AM, Wissel J. Classification of posture in poststroke upper limb spasticity: A potential decision tool for botulinum toxin A treatment? International Journal of Rehabilitation Research 2012;35:227-233.

10. Marciniak C. Poststroke hypertonicity: Upper limb assessment and treatment. Topics in Stroke Rehabilitation 2011;18:179-194.

11. Urban PP, Wolf $T$, Uebele M, Marx JJ, Vogt T, Stoeter P, Bauermann T, Weibrich C, Vucurevic GD, Schneider A, Wissel J. Occurence and clinical predictors of spasticity after ischemic stroke. Stroke 2010;41:2016-2020.

12. Coupar F, Pollock A, Rowe P, Weir C, Langhorne P. Predictors of upper limb recovery after stroke: A systematic review and metaanalysis. Clinical Rehabilitation 2012;26:291-313.

13. Duncan PW, Zorowitz R, Bates B, Choi JY, Glasberg JJ, Graham GD, Katz RC, Lamberty K, Reker D. Management of adult stroke rehabilitation care: A clinical practice guideline. Stroke 2005;36: e100-143.

14. Brown P. Pathophysiology of spasticity. Journal of Neurology, Neurosurgery \& Psychiatry 1994;57:773-777.

15. Doan QV, Brashear A, Gillard PJ, Varon SF, Vandenburgh AM, Turkel CC, Elovic EP. Relationship between disability and healthrelated quality of life and caregiver burden in patients with upper limb poststroke spasticity. Polymyalgia Rheumatica 2012;4:4-10.

16. Ivanhoe $\mathrm{C}$, Reistetter T. Spasticity: The misunderstood part of the upper motor neuron syndrome. American Journal of Physical Medicine \& Rehabilitation 2004;83:S3-S9.

17. Sheean G. The pathophysiology of spasticity. European Journal of Neurology 2002;9:3-9.

18. Soyuer F, Öztürk A. The effect of spasticity, sense and walking aids in falls of people after chronic stroke. Disability \& Rehabilitation 2007;29:679-687.

19. Binkofski F, Seitz RJ, Arnold S, Classen J, Benecke R, Freund HJ. Thalamic metbolism and corticospinal tract integrity determine motor recovery in stroke. Annals of Neurology 1996;39:460-470.

20. Pandyan A, Gregoric M, Barnes M. Spasticity: Clinical perceptions, neurological realities and meaningful measurement. Disability \& Rehabilitation 2005;27:2-6.

21. Marque $\mathrm{P}$, Simonetta-Moreau $\mathrm{M}$, Maupas E, Roques CF. Facilitation of transmission in heteronymous group II pathways in spastic hemiplegic patients. Journal of Neurology, Neurosurgery \& Psychiatry 2001;70:36-42. 
22. Averbeck BB, Chafee MV, Crowe DA, Georgopoulos AP. Neural activity in prefrontal cortex during copying geometrical shapes. I. Single cells encode shape, sequence, and metric parameters. Experimental Brain Research 2003;150:127-141.

23. Hanakawa T, Immisch I, Toma K, Dimyan MA, Van Gelderen P, Hallett M. Functional properties of brain areas associated with motor execution and imagery. Journal of Neurophysiology 2003;89: 989-1002.

24. Kalaska JF, Cisek P, Gosselin-Kessiby N. Mechanisms of selection and guidance of reaching movements in the parietal lobe. Advances in Neurology 2003;93:97-119.

25. Sirigu A, Daprati E, Ciancia S, Giraux P, Nighoghossian N, Posada A, Haggard P. Altered awareness of voluntary action after damage to the parietal cortex. Nature Neuroscience 2004;7: 80-84.

26. Sirigu A, Duhamel JR, Cohen L, Pillon B, Dubois B, Agid Y. The mental representation of hand movements after parietal cortex damage. Science 1996;273:1564-1568.

27. Ward NS, Brown MM, Thompson AJ, Frackowiak RS. Neural correlates of motor recovery after stroke: A longitudinal fMRI study. Brain 2003;126:2476-2496.

28. Newham DJ, Hsiao SF. Knee muscle isometric strength, voluntary activation and antagonist co-contraction in the first six months after stroke. Disability \& Rehabilitation 2001;23:379-386.

29. Riley NA, Bilodeau M. Changes in upper limb joint torque patterns and EMG signals with fatigue following a stroke. Disability \& Rehabilitation 2002;24:961-969.

30. Gemperline JJ, Allen S, Walk D, Rymer WZ. Characteristics of motor unit discharge in subjects with hemiparesis. Muscle \& Nerve 1995; 18:1101-1114.

31. Rosenfalck A, Andreassen S. Impaired regulation of force and firing pattern of single motor units in patients with spasticity. Journal of Neurology, Neurosurgery \& Psychiatry 1980;43: 907-916.

32. Jakobsson F, Grimby L, Edstrom L. Motoneuron activity and muscle fibre type composition in hemiparesis. Scandinavian Journal of Rehabilitation Medicine 1992;24:115-119.

33. Berg HE, Larsson L, Tesch PA. Lower limb skeletal muscle function after 6 wk of bed rest. Journal of Applied Physiology 1997;82:182-188.

34. Ferretti G, Berg HE, Minetti AE, Moia C, Rampichini S, Narici MV. Maximal instantaneous muscular power after prolonged bed rest in humans. Journal of Applied Physiology 2001;90:431-435.

35. McLachlan EM. Rapid atrophy of mouse soleus muscles after tenotomy depends on an intact innervation. Neuroscience Letters 1981;25:269-274.

36. McLachlan EM, Chua M. Rapid adjustment of sarcomere length in tenotomized muscles depends on an intact innervation. Neuroscience Letters 1983;35:127-133.

37. McLachlan EM. Atrophic effects of proximal tendon transection with and without denervation on mouse soleus muscles. Experimental Neurology 1983;81:651-668.

38. Williams PE, Goldspink G. Connective tissue changes in immobilised muscle. Journal of Anatomy 1984;138:343-350.

39. Esquenazi A. Evaluation and management of spastic gait in patients with traumatic brain injury. Journal of Head Trauma Rehabiliation 2004;19:109-118.

40. Bohannon R, Smith M. Inter rater reliability of a modified Ashworth Scale of muscle spasticity. Physical Therapy 1987;67: 206-207.

41. Tardieu G, Shentoub S, Delarue R. A la recherche d'une technique de mesure de la spasticité. Revista de Neurología 1954;91:143-144.

42. Held J, Pierrot-Deseilligny E. Reeducation Motrice des Affections Neurologiques. Paris: J.B. Baillères; 1969.

43. Pandyan A, et al. A review of the properties and limitations of the Ashworth and modified Ashworth Scales as measures of spasticity. Clinical Rehabilitation 1999;13:373-383.

44. Brashear A, et al. Intramuscular injection of botulinum toxin for the treatment of wrist and finger spasticity after a stroke. New England Journal of Medicine 2002;347:395-400.

45. Brashear A, Zafonte R, Corcoran M, Galvez-Jimenez N, Gracies JM, Gordon MF, McAfee A, Ruffing K, Thompson B, Williams M, Lee $\mathrm{CH}$, Turkel C. Inter- and intrarater reliability of the Ashworth Scale and the Disability Assessment Scale in patients with upper- limb poststroke spasticity. Archives of Physical Medicine \& Rehabilitation 2002:83:1349-1354.

46. Gracies JM, Fitzpatrick R, Wilson L, Burke D, Gandevia SC. Lycra garments designed for patients with upper limb spasticity: Mechanical effects in normal subjects. Archives of Physical Medicine \& Rehabilitation 1997;78:1066-1071.

47. Lee KC, Carson, L, Kinnin, E, Patterson, V. The Ashworth Scale: A reliable and reproducible method of measuring spasticity. Journal of Neurological Rehabilitation 1989;3:205-209.

48. Ghotbi N, Nakhostin Ansari N, Naghdi S, Hasson S. Measurement of lower-limb muscle spasticity: Intrarater reliability of Modified Modified Ashworth Scale. Journal of Rehabilitation Researh \& Development 2011;48:83-88.

49. Mehrholz J, Major Y, Meissner D, Sandi-Gahun S, Koch R, Pohl M. The influence of contractures and variation in measurement stretching velocity on the reliability of the Modified Ashworth Scale in patients with severe brain injury. Clinical Rehabilitation 2005; 19:63-72.

50. Gracies JM, Burke K, Clegg NJ, Browne R, Rushing C, Fehlings D, Matthews D, Tilton A, Delgado MR. Reliability of the Tardieu Scale for assessing spasticity in children with cerebral palsy. Archives of Physical Medicine \& Rehabilitation 2010;91:421-428.

51. Thakker MM, Rubin PA. Pharmacology and clinical applications of botulinum toxins A and B. International Ophthalmology Clinics 2004;44:147-163.

52. Boyd R, Graham HK. Objective measurement of clinical findings in the use of botulinum toxin type $\mathrm{A}$ in the management of spasticity in children with cerebral palsy. European Journal of Neurology 1999;6:23-36.

53. Mehrholz J, Wagner K, Meissner D, Grundmann K, Zange C, Koch R, Pohl M. Reliability of the Modified Tardieu Scale and the Modified Ashworth Scale in adult patients with severe brain injury: A comparison study. Clinical Rehabilitation 2005;19:751-759.

54. Yelnik AP, Simon O, Parratte B, Gracies JM. How to clinically assess and treat muscle overactivity in spastic paresis. Journal of Rehabilitation Medicine 2010;42:801-807.

55. Katz RT, Rovai GP, Brait C, Rymer WZ. Objective quantification of spastic hypertonia: Correlation with clinical findings. Archives of Physical Medicine \& Rehabilitation 1992;73:339-347.

56. Gracies JM, Marosszeky JE, Renton R, Sandanam J, Gandevia SC, Burke D. Short-term effects of dynamic lycra splints on upper limb in hemiplegic patients. Archives of Physical Medicine \& Rehabilitation 2000;81:1547-1555.

57. King T. A scale for more definitive measurement of hypertonicity. Paper presented at the Occupational Therapy Forum, Stockholm, 8-12 May, 1987.

58. Copley J, Kuipers K. Management of upper limb hypertonicity. Texas: Therapy Skill Builders; 1999. p 308.

59. Gregson JM, Leathley M, Moore AP, Sharma AK, Smith TL, Watkins CL. Reliability of the Tone Assessment Scale and the modified Ashworth scale as clinical tools for assessing poststroke spasticity. Archives of Physical Medicine \& Rehabilitation 1999; 80:1013-1016.

60. Granger CV, Hamilton BB, Gresham GE. The stroke rehabilitation outcome study-Part I: General description. Archives of Physical Medicine \& Rehabilitation 1988;69:506-509.

61. Granger CV, Hamilton BB, Gresham GE, Kramer AA. The stroke rehabilitation outcome study: Part II. Relative merits of the total Barthel index score and a four-item subscore in predicting patient outcomes. Archives of Physical Medicine \& Rehabilitation 1989; 70:100-103.

62. Bhakta BB, Cozens JA, Chamberlain MA, Bamford JM. Impact of botulinum toxin type A on disability and carer burden due to arm spasticity after stroke: A randomised double blind placebo controlled trial. Journal of Neurology, Neurosurgery \& Psychiatry 2000;69:217-221.

63. Voerman GE, Gregoric M, Hermens HJ. Neurophysiological methods for the assessment of spasticity: The Hoffmann reflex, the tendon reflex, and the stretch reflex. Disability \& Rehabilitation 2005;27:33-68.

64. Bishop B, Machover S, Johnston R, Anderson M. A quantitative assessment of gamma-motoneuron contribution to the achilles tendon reflex in normal subjects. Archives of Physical Medicine \& Rehabilitation 1968;49:145-154. 
65. Nielsen J, Petersen N, Ballegaard M, Biering-Sørensen F, Kiehn O. H-reflexes are less depressed following muscle stretch in spastic spinal cord injured patients than in healthy subjects. Experimental Brain Research 1993;97:173-176.

66. Decq P, Filipetti P, Lefaucheur JP. Evaluation of spasticity in adults. Operative technique in Neurosurgery 2005;7:100-108.

67. Crone C, Johnsen LL, Biering-Sørensen F, Nielsen JB. Appearance of reciprocal facilitation of ankle extensors from ankle flexors in patients with stroke or spinal cord injury. Brain 2003;126:495-507.

68. Senkárová Z, Hlustík P, Otruba P, Herzig R, Kanovský P. Modulation of cortical activity in patients suffering from upper arm spasticity following stroke and treated with botulinum toxin A: An fMRI study. Journal of Neuroimaging 2010;20:9-15.

69. Tomášová Z, Hluštík P, Král M, Otruba P, Herzig R, Krobot A, Kaňovský P. Cortical activation changes in patients suffering from post-stroke arm spasticity and treated with botulinum toxin A. Journal of Neuroimaging 2011. Dec 30. doi: 10.1111/j.15526569.2011.00682.x. [Epub ahead of print].

70. Nelles G, Jentzen W, Jueptner M, Müller S, Diener HC. Arm training induced brain plasticity in stroke studied with serial positron emission tomography. Neuroimage 2001;13:1146-1154.

71. Struppler A, Binkofski F, Angerer B, Bernhardt M, Spiegel S, Drzezga A, Bartenstein P. A fronto-parietal network is mediating improvement of motor function related to repetitive peripheral magnetic stimulation: A PET-H2O15 study. Neuroimage 2007; 36(Suppl 2):T174-186.

72. Carey LM, Abbott DF, Egan GF, O'Keefe GJ, Jackson GD, Bernhardt J, Donnan GA. Evolution of brain activation with good and poor motor recovery after stroke. Neurorehabilitation \& Neural Repair 2006;20:24-41.

73. Watanabe T. The role of therapy in spasticity management. American Journal of Physical Medicine \& Rehabilitation 2004; 83(Suppl 10):S45-49.

74. Gracies JM. Physical modalities other than stretch in spastic hypertonia. Physical Medicine Rehabilitation Clinics of North America 2001;12:769-792, vi.

75. Bovend'Eerdt TJ, Newman M, Barker K, Dawes H, Minelli C, Wade DT. The effects of stretching in spasticity: A systematic review. Archives of Physical Medicine \& Rehabilitation 2008;89: 1395-1406.

76. Harvey L, Herbert R, Crosbie J. Does stretching induce lasting increases in joint ROM? A systematic review. Physiotherapy Research International 2002;7:1-13.

77. Katalinic OM, Harvey LA, Herbert RD. Stretch for the treatment and prevention of contractures. Phys Ther 2011;91(1):11-24.

78. Watt J, Sims D, Harckham F, Schmidt L, McMillan A, Hamilton J. A prospective study of inhibitive casting as an adjunct to physiotherapy for cerebral-palsied children. Developmental Medicine \& Child Neurology 1986;28:480-488.

79. Lannin NA, Novak I, Cusick A. A systematic review of upper extremity casting for children and adults with central nervous system motor disorders. Clinical Rehabilitation 2007;21:963-976.

80. Morris SL, Dodd KJ, Morris ME. Outcomes of progressive resistance strength training following stroke: A systematic review. Clinical Rehabilitation 2004;18:27-39.

81. Sunnerhagen KS, Olver J, Francisco GE. Assessing and treating functional impairment in poststroke spasticity. Neurology 2013; 80(3 Suppl 2):S35-44.

82. Bobath B. The application of physiological principles to stroke rehabilitation. Practitioner 1979;223:793-794.

83. Ansari NN, Naghdi S. The effect of Bobath approach on the excitability of the spinal alpha motor neurones in stroke patients with muscle spasticity. Electromyography \& Clinical Neurophysiology 2007;47:29-36.

84. Dias D, Laíns J, Pereira A, Nunes R, Caldas J, Amaral C, Pires S, Costa A, Alves P, Moreira M, Garrido N, Loureiro L. Can we improve gait skills in chronic hemiplegics? A randomised control trial with gait trainer. Eura Medicophys 2007;43:499-504.

85. Neuhaus BE, Ascher ER, Coullon BA, Donohue MV, Einbond A, Glover JM, Goldberg SR, Takai VL. A survey of rationales for and against hand splinting in hemiplegia. American Journal of Occupational Therapy 1981;35:83-90.

86. Basaran A, Emre U, Karadavut KI, Balbaloglu O, Bulmus N. Hand splinting for poststroke spasticity: A randomized controlled trial. Topics in Stroke Rehabilitation 2012;19:329-337.
87. Alabdulwahab SS, Al-Gabbani M. Transcutaneous electrical nerve stimulation of hip adductors improves gait parameters of children with spastic diplegic cerebral palsy. NeuroRehabilitation 2010;26: $115-122$.

88. Ring H, Weingarden $\mathrm{H}$. Neuromodulation by functional electrical stimulation (FES) of limb paralysis after stroke. Acta Neurochirurgica Supplement 2007;97:375-380.

89. Sahin N, Ugurlu H, Albayrak I. The efficacy of electrical stimulation in reducing the post-stroke spasticity: A randomized controlled study. Disability \& Rehabilitation 2012;34:151-156.

90. Lin Z, Yan T. Long-term effectiveness of neuromuscular electrical stimulation for promoting motor recovery of the upper extremity after stroke. Journal of Rehabilitation Medicine 2011;43:506-510.

91. Yan T, Hui-Chan CW. Transcutaneous electrical stimulation on acupuncture points improves muscle function in subjects after acute stroke: A randomized controlled trial. Journal of Rehabilitation Medicine 2009;41:312-316.

92. Levin MF, Hui-Chan CW. Relief of hemiparetic spasticity by TENS is associated with improvement in reflex and voluntary motor functions. Electroencephalography \& Clinical Neurophysiology 1992;85:131-142.

93. Sahin N, Ugurlu H, Karahan AY. Efficacy of therapeutic ultrasound in the treatment of spasticity: A randomized controlled study. NeuroRehabilitation 2011;29:61-66.

94. Wu D, Qian L, Zorowitz RD, Zhang L, Qu Y, Yuan Y. Effects on decreasing upper-limb post-stroke muscle tone using transcranial direct current stimulation: A Randomized Sham-Controlled Study. Archives of Physical Medicine \& Rehabilitation 2013;94(1):1-8.

95. Hulme A, MacLennan WJ, Ritchie RT, John VA, Shotton PA. Baclofen in the elderly stroke patient its side-effects and pharmacokinetics. European Journal of Clinical Pharmacology 1985;29: 467-469.

96. Jamous A, Kennedy P, Psychol C, Grey N. Psychological and emotional effects of the use of oral baclofen: A preliminary study. Paraplegia 1994;32:349-353.

97. Goldstein EM. Spasticity management: An overview. Journal of Child Neurology 2001;16:16-23.

98. Lapeyre E, Kuks JB, Meijler WJ. Spasticity: Revisiting the role and the individual value of several pharmacological treatments. NeuroRehabilitation 2010;27:193-200.

99. Hesse S, Werner C. Poststroke motor dysfunction and spasticity: Novel pharmacological and physical treatment strategies. CNS Drugs 2003;17:1093-1107.

100. Formica A, Verger K, Sol JM, Morralla C. [Gabapentin for spasticity: A randomized, double-blind, placebo-controlled trial]. Medicina Clinica (Barcelona) 2005;124:81-85.

101. Wagstaff AJ, Bryson HM. Tizanidine. A review of its pharmacology, clinical efficacy and tolerability in the management of spasticity associated with cerebral and spinal disorders. Drugs 1997;53:435-452.

102. Gelber DA, Good DC, Dromerick A, Sergay S, Richardson M. Open-label dose-titration safety and efficacy study of tizanidine hydrochloride in the treatment of spasticity associated with chronic stroke. Stroke 2001;32:1841-1846.

103. Whelan MA, Delgado MR. Practice parameter: Pharmacologic treatment of spasticity in children and adolescents with cerebral palsy (an evidence-based review): Report of the Quality Standards Subcommittee of the American Academy of Neurology and the Practice Committee of the Child Neurology Society. Neurology 2010;74:336-343.

104. Olvey EL, Armstrong EP, Grizzle AJ. Contemporary pharmacologic treatments for spasticity of the upper limb after stroke: A systematic review. Clinical Therapy 2010;32: 2282-2303.

105. Zhao F, Li P, Chen SR, Louis CF, Fruen BR. Dantrolene inhibition of ryanodine receptor $\mathrm{Ca} 2+$ release channels. Molecular mechanism and isoform selectivity. Journal of Biological Chemistry 2001;276:13810-13816.

106. Chan CH. Dantrolene sodium and hepatic injury. Neurology 1990; 40:1427-1432.

107. Elovic EP, Esquenazi A, Alter KE, Lin JL, Alfaro A, Kaelin DL. Chemodenervation and nerve blocks in the diagnosis and management of spasticity and muscle overactivity. American Academy of Physical Medicine and Rehabilitation (AAPM\&R) 2009;1:842-851. 
108. Yelnik AP, Simon O, Bensmail D, Chaleat-Valayer E, Decq P, Dehail P, Quentin V, Marque P, Parratte B, Pellas F, Rousseaux M, Trocello JM, Uzzan M, Dumarcet N. Drug treatments for spasticity. Annals of Physical and Rehabilitation Medicine 2009; 52:746-756.

109. Patel AT. Successful treatment of long-term, poststroke, upperlimb spasticity with onabotulinumtoxinA. Physical Therapy 2011; 91:1636-1641.

110. McCrory P, Turner-Stokes L, Baguley IJ, De Graaff S, Katrak P, Sandanam J, Davies L, Munns M, Hughes A. Botulinum toxin A for treatment of upper limb spasticity following stroke: A multicentre randomized placebo-controlled study of the effects on quality of life and other person-centred outcomes. Journal of Rehabilitation Medicine 2009;41:536-544.

111. Simon O, Yelnik AP. Managing spasticity with drugs. European Jornal of Physical \& Rehabiliation Medicine 2010;46: 401-410.

112. Bakheit AM, Thilmann AF, Ward AB, Poewe W, Wissel J, Muller J, Benecke R, Collin C, Muller F, Ward CD, Neumann C. A randomized, double-blind, placebo-controlled, dose-ranging study to compare the efficacy and safety of three doses of botulinum toxin type A (Dysport) with placebo in upper limb spasticity after stroke. Stroke 2000;31:2402-2406.

113. Simpson DM, Gracies JM, Graham K, Hallett M, Miyasaki J, Naumann M, Russman B, Simpson L, So Y. Assessment: Botulinum neurotoxin for the treatment of spasticity (an evidence-based review). Neurology 2009;73:736-737; author reply $737-738$.

114. Burbaud P, Wiart L, Dubos JL, Gaujard E, Debelleix X, Joseph PA, Mazaux JM, Bioulac B, Barat M, Lagueny A. A randomised, double blind, placebo controlled trial of botulinum toxin in the treatment of spastic foot in hemiparetic patients. Journal of Neurology, Neurosurgery \& Psychiatry 1996;61: 265-269.

115. Simpson DM, Gracies JM, Yablon SA, Barbano R, Brashear A. Botulinum neurotoxin versus tizanidine in upper limb spasticity: A placebo-controlled study. Journal of Neurology, Neurosurgery \& Psychiatry 2009;80:380-385.
116. Pedreira G, Cardoso E, Melo A. Botulinum toxin type A for refractory post-stroke shoulder pain. Arquivos de NeuroPsiquiatria 2008;66:213-215.

117. Sheean G, Lannin NA, Turner-Stokes L, Rawicki B, Snow BJ. Botulinum toxin assessment, intervention and after-care for upper limb hypertonicity in adults: International consensus statement. Eurpean Journal of Neurology 2010;17(Suppl 2):74-93.

118. Brashear A, McAfee AL, Kuhn ER, Fyffe J. Botulinum toxin type B in upper-limb poststroke spasticity: A double-blind, placebocontrolled trial. Archives of Physical Medicine \& Rehabilitation 2004;85:705-709.

119. Wolf SL, Milton SB, Reiss A, Easley KA, Shenvi NV, Clark PC. Further assessment to determine the additive effect of botulinum toxin type $\mathrm{A}$ on an upper extremity exercise program to enhance function among individuals with chronic stroke but extensor capability. Archives of Physical Medicine \& Rehabilitation 2012;93:578-587.

120. Penn RD. Intrathecal baclofen for spasticity of spinal origin: Seven years of experience. Journal of Neurosurgery 1992;77:236-240.

121. Van Schaeybroeck P, Nuttin B, Lagae L, Schrijvers E, Borghgraef C, Feys P. Intrathecal baclofen for intractable cerebral spasticity: A prospective placebo-controlled, double-blind study. Neurosurgery 2000;46:603-609; discussion 609-612.

122. Stempien L, Tsai T. Intrathecal baclofen pump use for spasticity: A clinical survey. American Journal of Physical Medicine \& Rehabilitation 2000;79:536-541.

123. Chambers HG. The surgical treatment of spasticity. Muscle \& Nerve Supplement 1997;6:S121-128.

124. Farmer JP, Sabbagh AJ. Selective dorsal rhizotomies in the treatment of spasticity related to cerebral palsy. Child's Nervous System 2007;23:991-1002.

125. Gracies JM. Pathophysiology of spastic paresis. I: Paresis and soft tissue changes. Muscle \& Nerve 2005;31:535-551.

126. Satkunam LE. Rehabilitation medicine: 3. Management of adult spasticity. Canadian Medical Association Journal 2003;169: 1173-119. 